\title{
Characterisation of PM2.5 concentrations and turbulent fluxes on a island of the Venice lagoon using high temporal resolution measurements
}

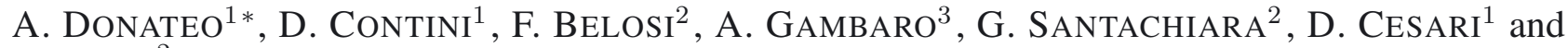 \\ F. PRODI ${ }^{2}$
}

${ }^{1}$ CNR-ISAC, Istituto di Scienze dell'Atmosfera e del Clima, Lecce, Italy

${ }^{2}$ CNR-ISAC, Istituto di Scienze dell' Atmosfera e del Clima, Bologna, Italy

${ }^{3}$ Environmental Sciences Department, Ca' Foscari University of Venice, Venice, Italy

(Manuscript received November 21, 2011; in revised form June 23, 2012; accepted June 25, 2012)

\begin{abstract}
This work presents an analysis of PM2.5 concentrations and vertical turbulent fluxes on an island of the Venice lagoon. Data were collected during three measurement campaigns in spring, summer and winter periods. Measurements were taken with a high-resolution optical PM2.5 detector, coupled with a micrometeorological station that allowed the evaluation of the vertical turbulent fluxes of PM2.5 using the eddy-correlation technique. The main objective of this paper is to analyse the daily and seasonal pattern in PM2.5 concentrations and fluxes and to discuss their correlation with the main meteorological and micrometeorological parameters using high temporal resolution measurements. Observed data showed a seasonal pattern in turbulent fluxes with daytime average positive value during winter and negative during summer. Deposition velocities, ranged from -60 to $20 \mathrm{~mm} / \mathrm{s}$, appeared to be mainly influenced by atmospheric stability. There were larger emissions in cases of high wind velocities blowing from water sector indicating a significant potential contribution of sea spray to PM2.5 fluxes. The local atmospheric circulation, due to the orography of the area, was characterised by diurnal winds coming from the Adriatic Sea and nocturnal wind coming from the Alps. This circulation influenced deposition velocity creating an increase of negative fluxes in the morning at the starting of the sea breeze. A diurnal pattern in concentration has been observed and it is similar for all three measurement campaigns, with higher concentrations in nocturnal periods. The daily pattern was investigated in terms of its correlation with meteorological and micro-meteorological parameters, and was found highly correlated with the diurnal pattern of boundary layer height (BLH) and with relative humidity.
\end{abstract}

\section{Introduction}

The Venice lagoon is the largest wetland in the Mediterranean (about $550 \mathrm{~km}^{2}$ of shallow water), and it is characterized by different subsystems which determine its great complexity and diversity. It can be considered a transition ecosystem between land and sea, continuously exchanging matter and energy with drainage basin and the Adriatic Sea. The contamination of the Venice lagoon received much attention in recent decades. The lagoon has a long history of industrial activity and the close industrial area of Porto Marghera is heavily populated by chemical and oil refining plants. Over the last two decades, the decline of the chemical industry and the adoption of new emission control and abatement technologies significantly reduced the aqueous and gaseous industrial emissions in this area (DALla VALLE et al., 2003). Several studies investigated the levels of atmospheric chemical pollutants in the Venice lagoon, in terms of long-time average (GAMBARO et al., 2004; BETTIOL et al., 2005; RossinI et al., 2005) and aerosol concentration and composition (GAMBARO et al., 2007;

\footnotetext{
${ }^{*}$ Corresponding author: Antonio Donateo, Istituto di Scienze dell'Atmosfera e del Clima, U.O.S. di Lecce Str. Prv. Lecce-Monteroni km 1.2, 73100 Lecce, Italy, e-mail: a.donateo@isac.cnr.it
}

RAMPAZZO et al., 2008; Prodi et al., 2009; STORTINI et al., 2009) and aerosol deposition (GUERZONI et al., 2004, SCAZZOLA et al., 2004; GUERZONI et al., 2005; Rossini et al., 2005; GAMBARO et al., 2009). This work was focused primarily on the short-term dynamical characteristics of the fine aerosol fraction (PM2.5). This has a great deal of interest for researchers due to its potential effects on the environment and human health, as confirmed by epidemiological studies (IBALD-MULLI et al., 2004; DONALDSON et al., 2005; BURGAN et al., 2010; Kelly and FusSell, 2011). Consequently, there have been significant efforts to measure the atmospheric concentration of particles of different size, as well as the turbulent fluxes that characterize aerosol exchanges between the atmosphere and surface in both rural (or forest) (GALLAGHER et al., 1997; BUZORIUS et al., 1998; GALLAGHER et al., 2002) and urban environments (DORSEY et al., 2002; MARTENSSON et al., 2006; Nemitz et al., 2008; SCHMidT and Klemm, 2008; JARVI et al., 2009). However, analysis of turbulent fluxes in lagoon areas are still scarce. In this work, mean concentrations and vertical turbulent fluxes of PM2.5 were measured with an optical detector, using the eddy covariance technique, in a background site on the Mazzorbo island in the Venice lagoon. The objective is to 
correlate the aerosol dynamics with the main meteorological and micrometeorological parameters of the area. This will allow, in principle, to determine which meteorological parameters (or group of parameters) have the largest influence on the dynamics of concentration and fluxes in the complex area of the Venice lagoon in which specific air masses circulations are present especially in the spring and summer seasons influencing the levels of PM2.5 concentrations. Measured patterns of concentration and turbulent fluxes show a clear influence of the boundary-layer height on observed concentrations and an influence of local breeze on deposition velocities and atmospheric stability. Further, a multivariate statistical analysis using Principal Component Analysis (PCA) has been performed to better put in evidence the correlations between meteorological parameters, PM2.5 concentrations and deposition velocity.

\section{Instrumentation, methodology and measurement site}

\subsection{Characterisation of the measurement site}

Measurements were performed at a background site placed on the island of Mazzorbo, in the Venice lagoon. The measurement site was a field $\left(45^{\circ} 29^{\prime} 09.5^{\prime \prime}\right.$ $\left.\mathrm{N}, 12^{\circ} 24^{\prime} 12.7^{\prime \prime} \mathrm{E}\right)$ located at about $8 \mathrm{~km} \mathrm{NE}$ of the Venice town. This site, shown in Figure 1a, was located very close (about $5 \mathrm{~m}$ ) to the water lagoon at the W-SW side, while in the other directions (north, east and south side), it was characterised by land for about $1-2 \mathrm{~km}$ with short vegetation, some small trees and one or two stores houses, although channels and water were also present in this area. Given the complexity of the site some calculations were performed separating measurements in two wind directions sectors. The first one (land sector) included wind direction between $300^{\circ}$ and $230^{\circ}$, and the second one (water sector) included directions between $230^{\circ}$ and $300^{\circ}$. Measurements were used to evaluate the displacement height $\mathrm{d}$ and the roughness height $z_{0}$ in the two sectors. The displacement height for the water sector was assumed to be zero, instead, for the land sector, $d$ was estimated using the method described in TODA and SugiTA (2003), based on the equation, valid for unstable cases $(L<0)$ :

$$
\varphi_{w}=\frac{\sigma_{w}}{u_{*}}=C_{1}\left(1-C_{2} \frac{z-d}{L}\right)^{1 / 3}
$$

where $\sigma_{w}$ and $u_{*}$ are, respectively, the standard deviation of vertical wind velocity and the friction velocity, $L$ is the Monin-Obukhov length, $z$ is the measurement height $(9.6 \mathrm{~m})$ and $C_{1}$ and $C_{2}$ are similarity constants. The similarity constant $C_{2}=3$ is taken from previous research work (PANOFSKY and DUTTON, 1984) and $C_{1}=1.20 \pm 0.01$ was obtained as a result of the fit of measured data to Eq. (2.1). The value of $d$ for land sector was $5.1 \pm 0.5 \mathrm{~m}$. The estimation of $z_{0}$ was performed
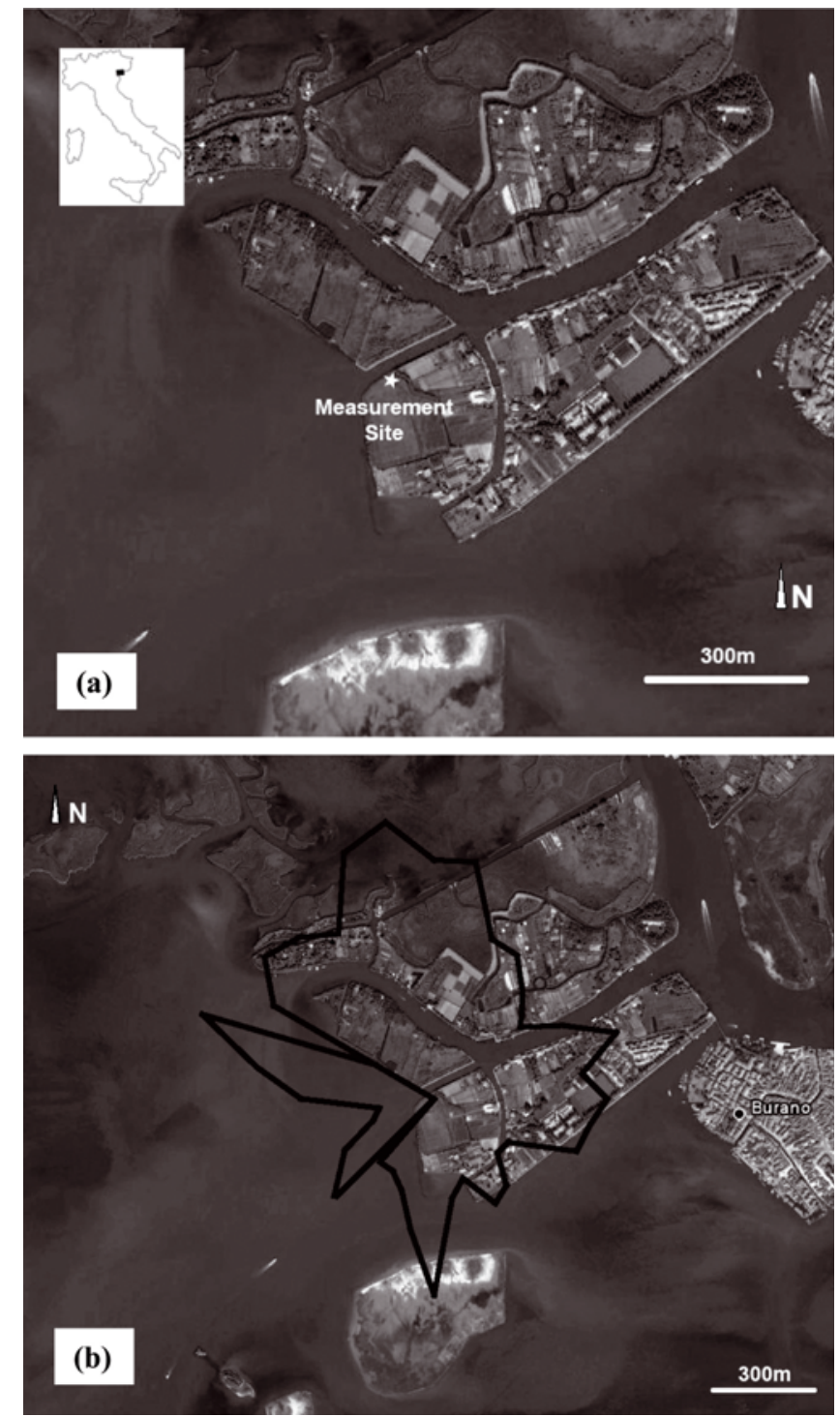

Figure 1: (a) Satellite map of the measurement site (white star) and the land use around. (b) Average contour of the footprint source area for fluxes is overlapped to the satellite map of the measurement site.

selecting data in near-neutral conditions and fitting them to the following parameterisation:

$$
U=\frac{u_{*}}{k} \ln \left(\frac{z-d}{z_{0}}\right)
$$

where $U$ is the mean wind velocity and $k=0.4$ is the von Karman constant. The uncertainty on $z_{0}$ was evaluated propagating the uncertainty coming from the fit of Eq. (2.2) and the estimated uncertainty in displacement height $d$. The estimated values of $z_{0}$ were $0.11 \pm 0.03$ $\mathrm{m}$ for land sector and $0.01 \pm 0.03 \mathrm{~m}$ for water sector. A simple and practical parameterisation for scalar passive tracer described in HsieH et al. (2000) was used to evaluate the source areas (footprints) for aerosol vertical fluxes, representing the area contributing to $50 \%$ of measured fluxes. For each 30 minutes period the footprint was evaluated using the wind-direction dependent 

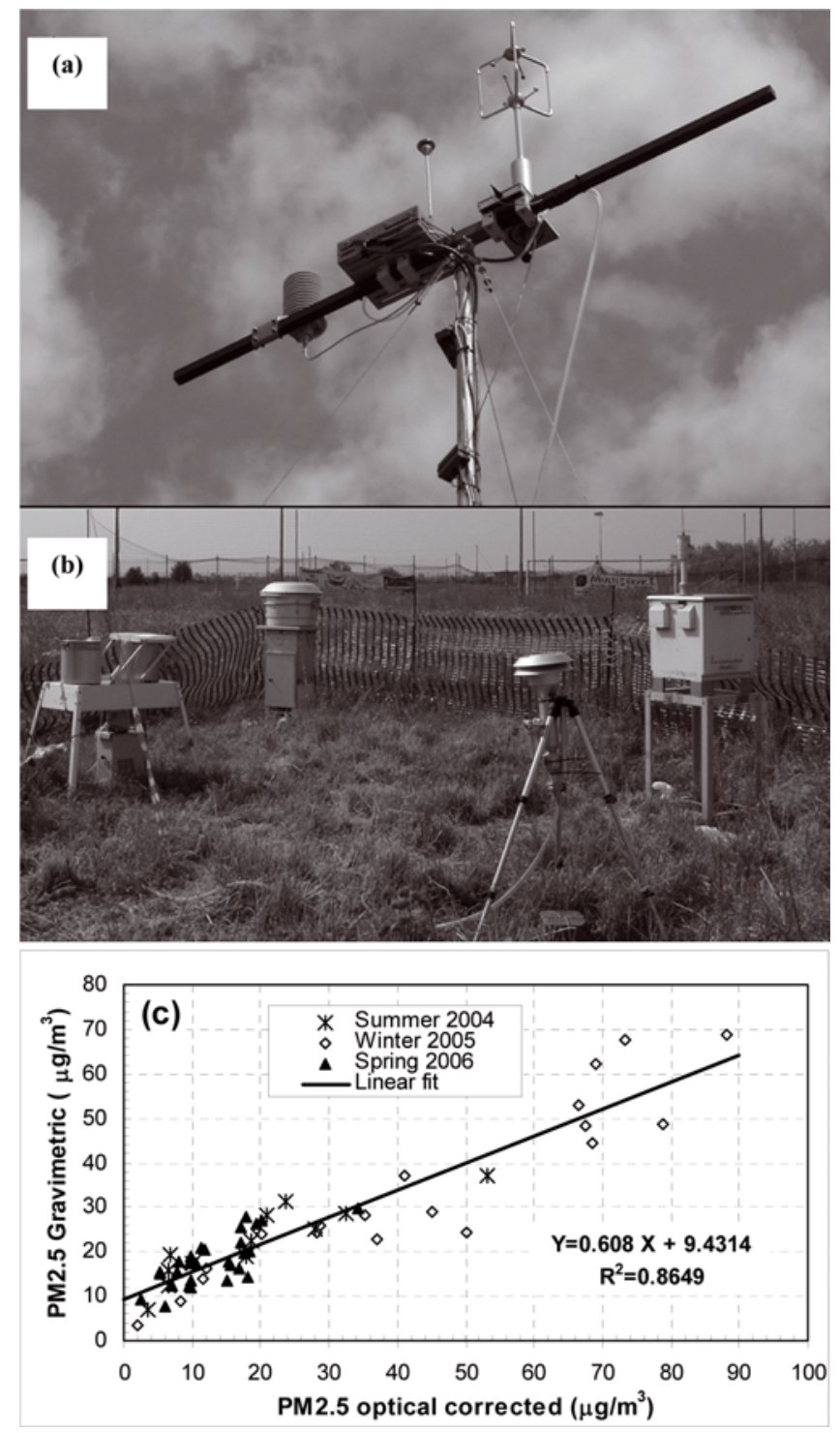

Figure 2: (a) Instrumental set-up used for real time measurements of PM2.5 concentrations and vertical turbulent fluxes. (b) Equipment for ground level gravimetric measurements of PM2.5. (c) Comparison of gravimetric PM2.5 concentration with $\mathrm{RH}$-corrected mass concentration, obtained from the nephelometer including a linear fit.

$z_{0}$ described previously. The results are reported in Figure $1 \mathrm{~b}$ in which an average contour of the source area was overlapped to the satellite map of the site. This contour line was obtained averaging the footprint values in 10 degrees bins of wind direction.

\subsection{Instruments and measurement site}

Three measurement campaigns were performed: the first measurement campaign (summer) in July 2004 ( $2^{\text {nd }}$ to $18^{\text {th }}$ ), the second campaign (winter) in February and March $2005\left(16^{\text {th }}\right.$ February to $15^{\text {th }}$ March) and the third campaign (spring) in May $2006\left(5^{\text {th }}\right.$ to $23^{\text {rd }}$ ). There were a total of 64 measurement days for all three campaigns. The measurement instruments (Figure 2a) were mounted on a horizontal bar placed at the top of a telescopic mast (Clark Mast SQT9/M) $9.6 \mathrm{~m}$ above the ground. The measuring station was based on a three-dimensional ultrasonic anemometer (R3 Gill Instruments Ltd, Lymington, UK), operating at $100 \mathrm{~Hz}$ in calibrated mode. Additional instruments included a slow-response $(<10 \mathrm{~s}$ according to manufacturer) thermo-hygrometer Rotronic MP100A (Campbell Scientific) and an electronic inclinometer (model FAS-A, Microstrain) mounted on the anemometer base to control the pitch and roll angles of the anemometer itself in real time $(30 \mathrm{~Hz})$. An optical sensor pDR1200 (Personal Data logging Real time Aerosol Monitor by Thermo Electron - Mie Corp.) was used to measure PM2.5 concentrations. The pDR-1200 was operating at $1 \mathrm{~Hz}$ with a pump (TECORA Bravo H-Plus) for active sampling; it was equipped with a cyclone $(2.5 \mu \mathrm{m}$ cut-off at the $4 \operatorname{lmin}^{-1}$ flow rate used, model GK2.05) (KENNY and GUSSMAN, 1997). The sampling point was about $30 \mathrm{~cm}$ away from the measuring volume of the ultrasonic anemometer. It was verified that the zero of the nephelometer can change of about $2-3 \mathrm{~g} / \mathrm{m}^{3}$ over a period of about 3 weeks, which is a typical time for a campaign, and that exist a delay $t_{0}$, about $2 \mathrm{~s}$, between change in mass concentration and the effective measure of pDR-1200. This delay has been also verified by searching the maximum of the absolute value of the correlation between the vertical wind velocity and the concentration time-series and it has been taken into account in the evaluation of the turbulent fluxes using the eddy-correlation method. Atmospheric aerosol can be highly hygroscopic and it can absorb water vapour at high relative humidity $(\mathrm{RH})$ changing dimension, density and optical properties; this process modifies the scattering and absorption coefficients of particles and then it modifies the response of the optical detector used (CHAKRABARTI et al., 2004). Therefore, measured concentrations were corrected, using the procedure described in DonATEO et al. (2006), to account for the role of RH. To test the quality of optical PM2.5 measurements, results were compared with those taken using the gravimetric method. Gravimetric measurement of PM2.5 concentrations were taken on a 24-hour basis, using a standard inlet (Figure 2b) operating at a flow-rate of $2.3 \mu \mathrm{m}^{3} / \mathrm{h}$ and collecting aerosol on $47 \mathrm{~mm}$ filters (in May 2006 there was also a sampler with a US-EPA inlet operating at $1 \mathrm{~m}^{3} / \mathrm{h}$ ). A comparison of simultaneously collected available data from pDR-1200 and gravimetric analyses gave an average PM2.5 gravimetric concentration of $24 \mu \mathrm{g} / \mathrm{m}^{3}$ and pDR-1200 measurements gave 49 $\mu \mathrm{g} / \mathrm{m}^{3}$ (uncorrected) and $23.9 \mathrm{~g} / \mathrm{m}^{3}$ with RH-correction. Results, having a Pearson correlation coefficient of 0.93 , are reported in Figure 2c.

\subsection{Post-processing of data}

Post-processing of data was based on 30-minute averages in the streamline reference system and the eddycorrelation procedure was used to estimate vertical tur- 
bulent momentum, energy and PM2.5 fluxes. The time series (PM2.5 concentration, wind velocity and sonic temperature) were treated with a linear detrending before the calculation of PM2.5 fluxes as $\left.F=<W^{\prime} C^{\prime}\right\rangle$, where $W$ is the vertical wind velocity, $C$ the PM2.5 concentration, the symbol $<>$ indicates a time average, the apex indicates a fluctuation of the variable. Calculated fluxes were used to evaluate the deposition velocity as $V_{d}=-F /<C>$.

The pDR-1200 first-order time response was enough (about $1.1 \mathrm{~s}$ ) to obtain valid information about the PM2.5 turbulent fluxes (DONATEO et al., 2006), nevertheless there were high-frequency losses on measured fluxes that were corrected using the procedure proposed in HoRst (1997). The average value of the correction was $27 \%$, with inter-quartile range between $25^{\text {th }}$ and $75^{\text {th }}$ percentile, IQR $=2 \%-37 \%$. This correction depends on stability, measurement height and wind velocity, however, the value found is comparable with the average correction found in other research works using eddy correlation with different instruments and different methods of correction. For example in ConTINI et al. (2012) an average correction of $33 \%$ was found in a urban site using a CPC with a time response of $1.3 \mathrm{~s}$. In DAMAY et al. (2009) an average correction of $30 \%$ is found using an ELPI (with $1 \mathrm{~Hz}$ resolution) in an eddycorrelation system.

A stationary test was performed using the method described in MAHRT (1998) to evaluate a non-stationary ratio (NR) calculated on the covariance between the PM2.5 concentration and vertical wind component time series. For stationary conditions, NR is approximately 1 and if NR is significantly larger than 1 , the time series can be considered non-stationary. In this work, the threshold for NR has been set at 2, which was reasonable according to the literature (CAVA et al., 2008). The percentage of non-stationary data, according to this characterization criterion, was equal to $5.0 \%$ in the summer campaign, $7.1 \%$ in the winter campaign and $6.3 \%$ in the spring campaign. The non-stationary periods were removed from the analysis.

The influence due to the water vapour effect on air density (WEBB et al., 1980) was estimated assuming that the temperature fluctuations were damped in the inlet line (PRYOR et al., 2008) using an estimation of the latent heat flux, that was not measured, using the Bowen ratio to estimate a lower limit to the Bowen ratio (B) the global solar radiation and the sensible heat fluxes were analyzed, so that the difference between them provide a maximum threshold for the latent heat fluxes. This, in turn, gives an average lower limit for B that results equal to 0.5 . This value is in agreement with measurements made in similar humid environments. For example, near a lake located in mid latitudes it was found an average B of 0.4 (MOMII and ITO, 2008) and a similar value about $0.4-0.5$ was obtained by MCJANNET et al. (2011) at Logan's Dam, which is an irrigation water storage. We also analyzed previously available data of sensible and latent heat fluxes in the area of Venice lagoon (MARTANO, 1996) finding a Bowen ratio of about 1 in winter period. Considering therefore as a reasonable range for $B$ the interval between 0.5 and 1 the average error due to the effect of air density fluctuations is between $3 \%$ and $6 \%$.

The instrument used in this work had its maximum response to particle with a mass median diameter between 0.7 and $1.2 \mu \mathrm{m}$ (CHAKRABARTI, 2004). Thereby, as already discussed, it was influenced by hygroscopic growth and shrink at relative humidity larger than $70 \%$. The correction used can have residual effects not compensated, especially on flux measurements (CONTINI et al., 2010). The residual effects were due to two different reasons: the correction was based on a slow-response detection of relative humidity (about $10 \mathrm{~s}$ ) therefore fast fluctuations were damped; the correction was evaluated as an average response of the detector over several independent measurement campaigns and not on the specific aerosol composition present at the time of the measurements. It is possible to give an evaluation of this residual error, due to the influence of RH on measured concentrations, following the procedure proposed in (CONTINI et al., 2010) based on the comparison of measurements corrected, $(V d)_{C A L C}$, and not corrected, $(V d)_{N C}$ for the effect of RH. The residual error on deposition velocity was estimated as:

$$
\begin{aligned}
& \Delta \mathrm{V}_{\mathrm{d}}=\left(\mathrm{V}_{\mathrm{d}}\right)_{\mathrm{CALC}}-\mathrm{V}_{\mathrm{d}}= \\
& \frac{(1-\beta)}{\beta}\left(\left(\mathrm{V}_{\mathrm{d}}\right)_{\mathrm{NC}}-\left(\mathrm{V}_{\mathrm{d}}\right)_{\mathrm{CALC}}\right)
\end{aligned}
$$

where $\beta$ was evaluated using the attenuation formula $\mathrm{A}(\tau)$, reported in HORST (1997), that provides the attenuation of fluxes measured with an instrument that have a first-order time response equal to $\tau$. In particular the fraction $\beta$ is equal to: $\beta=\frac{\mathrm{A}(\tau=10 \mathrm{~s})}{\mathrm{A}(\tau=1.1 \mathrm{~s})}$. In all the measurement campaigns analysed in this work, this residual error was generally lower than $1 \mathrm{~mm} / \mathrm{s}$ (in absolute value), in particular it was, on average, $0.44 \mathrm{~mm} / \mathrm{s}$ in summer period, $0.36 \mathrm{~mm} / \mathrm{s}$ in spring period. During the winter campaign the residual error was the smallest being 0.30 $\mathrm{mm} / \mathrm{s}$. As a conclusion the final error on measured fluxes is obtained adding this residual error to previously calculated error due to the fluctuations of air density.

\section{Results}

\subsection{Local circulation}

The hourly wind direction measured at $9.6 \mathrm{~m}$ above the ground was compared (Figure 3a) with the direction measured at $213 \mathrm{~m}$ above the ground using a sodar-rass system located at Porto Marghera (managed by Ente della Zona Industriale Porto Marghera, www.entezona.it). The two independent measurements 

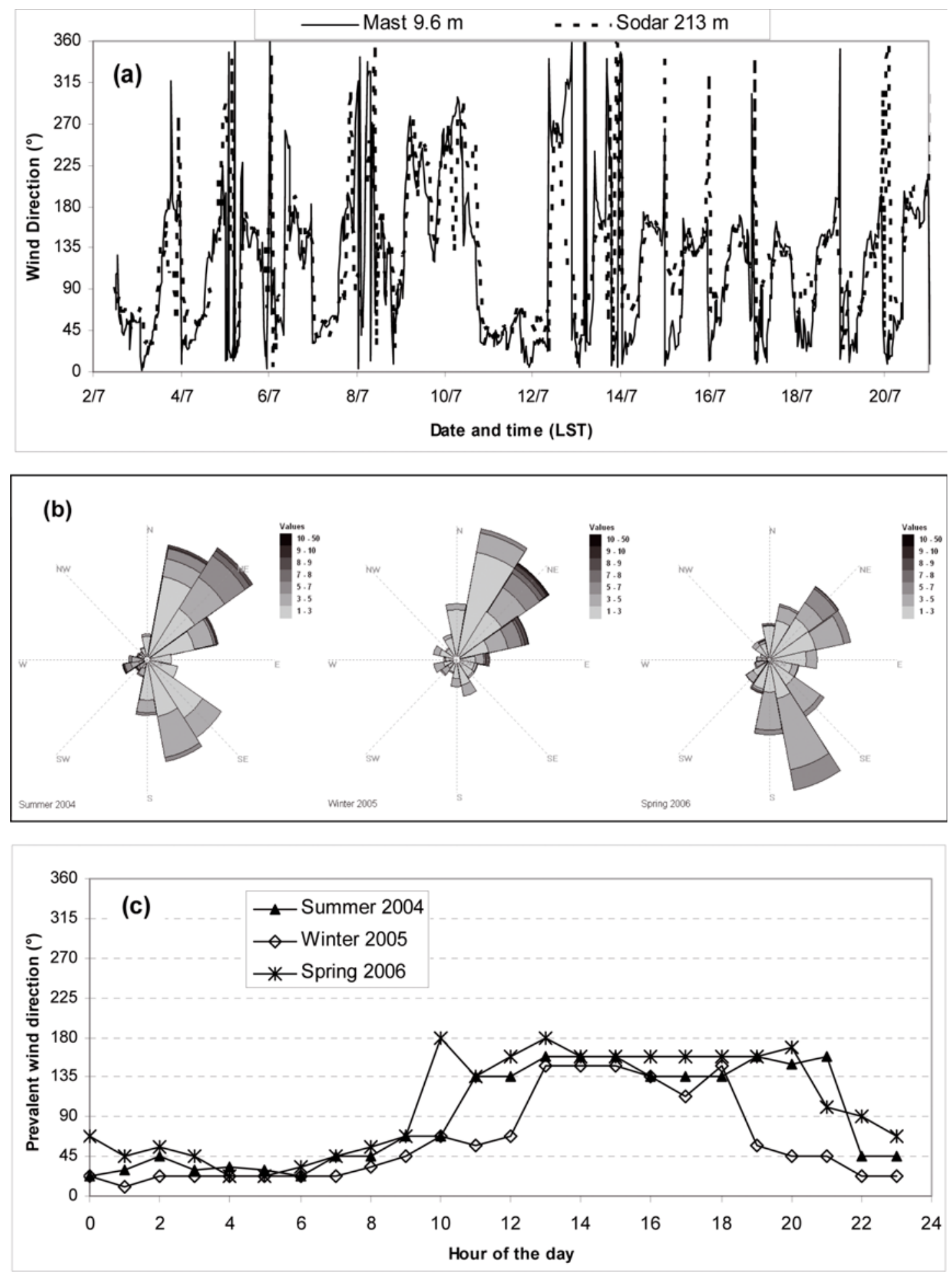

Figure 3: (a) Summer wind direction with the micrometeorological station compared with the direction measured at $213 \mathrm{~m}$ above the ground by the sodar-rass. (b) Wind roses of the different measurement campaigns. (c) Daily, hourly pattern of prevalent wind direction for the different measurement campaigns.

showed the same general pattern indicating that wind direction was usually quite stable until at least around 200-250 $\mathrm{m}$ above ground level even if the wind velocity was increasing with height. Especially in summer and spring periods, the wind direction behaviour followed a general circulation pattern, with wind blowing from NNE-NE during the night (from the direction of the Alps mountains) and wind blowing from SSESE during the day (from the Adriatic Sea). This pattern was in agreement with previous meteorological mea- 
Table 1: PM2.5 average concentrations and their standard deviations (in parentheses) for the three measurement campaigns and for the entire measurement periods, separating diurnal and nocturnal cases and separating low wind speed from high wind speed.

\begin{tabular}{|c|c|c|c|c|c|}
\hline$\left(\mu \mathrm{g} / \mathrm{m}^{3}\right)$ & $\begin{array}{c}\text { PM2.5 } \\
\text { (st.dev.) }\end{array}$ & $\begin{array}{c}\text { PM2.5 } \\
(\mathrm{U}<2 \mathrm{~m} / \mathrm{s})\end{array}$ & $\begin{array}{c}\text { PM2.5 } \\
(\mathrm{U}>2 \mathrm{~m} / \mathrm{s})\end{array}$ & $\begin{array}{l}\text { PM2.5 Diurnal } \\
(8 \text { am -- } 8 \text { pm) }\end{array}$ & $\begin{array}{l}\text { PM2.5 Nocturnal } \\
\text { (8 pm -- } 8 \text { am) }\end{array}$ \\
\hline Summer 2004 & $16.7(18.0)$ & 23.5 & 13.0 & 14.1 & 19.7 \\
\hline Winter 2005 & $41.8(31.6)$ & 50.0 & 37.6 & 36.3 & 48.8 \\
\hline Spring 2006 & $16.9(15.2)$ & 20.1 & 15.7 & 15.8 & 18.3 \\
\hline All data & $27.5(27.2)$ & 34.6 & 24.2 & 24.2 & 31.6 \\
\hline
\end{tabular}

surements near ground level (CAMUFFO, 1981). This type of wind circulation was more frequent and stable for several subsequent days in the summer and spring periods compared to winter. The wind roses, reported in Figure 3b, showed that the dominant wind direction during the winter was from the NE sector, but that some cases of southerly wind direction were present mainly limited to daytime hours. An analysis of the typical diurnal patterns in prevalent wind direction, on an hourly level (reported in Figure 3c), showed a daily trend with wind direction transition, changing from the NNE sector to the SSE in the morning between 9.00 am and 11.00 am and changing back from the SSE sector to the NNE in the evening between $8.00 \mathrm{pm}$ and $10.00 \mathrm{pm}$. In the winter, the change in wind direction was later in the morning and earlier in the evening. Wind speed often reached high values during nocturnal measurements, with peaks around $10 \mathrm{~m} / \mathrm{s}$ (on $30 \mathrm{~min}$ average). High speeds were associated with several different directions and relatively windy conditions have been seen both during the day and night.

\subsection{PM2.5 mass concentration and vertical turbulent fluxes}

The average observed PM2.5 concentrations were reported in Table 1, together with an analysis of concentration changes as a function of wind speed and sampling time. A seasonal pattern was clearly evident, with higher concentrations during the winter, in agreement with observations carried out by the air quality monitoring network in Venice (Regional Protection Agency, ARPAV, www.arpa.veneto.it), and also with results obtained in other measurement sites in northern Italy and reported in literature (MARCAZZAN et al., 2001, MARCAZZAN et al., 2003). It was interesting to observe a Pearson correlation coefficient of 0.88 between our daily PM2.5 data and the PM10 measurements of the Sacca Fisola monitoring station $\left(45^{\circ} 25^{\prime} 39.80^{\prime \prime} \mathrm{N}, 12^{\circ} 18^{\prime} 54.58^{\prime \prime} \mathrm{E}\right.$, managed by ARPAV) and that of 0.82 between PM2.5 data and the PTS measured at the background monitoring station of Campagna Lupia $\left(45^{\circ} 20^{\prime} 50.94 \prime \mathrm{N}, 12^{\circ}\right.$ 07' 05.27'E, managed by Ente della Zona Industriale di Porto Marghera). This spatial homogeneity of concentrations in the lagoon area was mainly due to the influence of local circulation of air masses that favoured the mixing of pollutants released from the different local sources. On the other hand, the high correlation co-
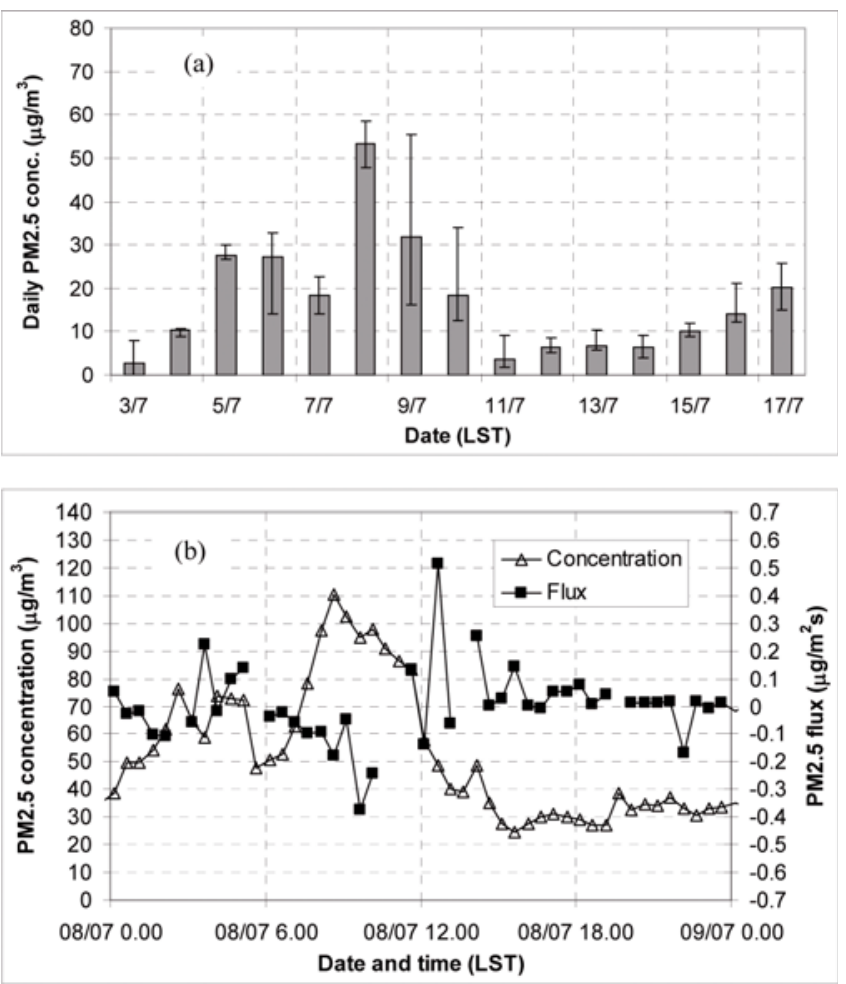

Figure 4: (a) Daily PM2.5 concentration average for summer campaign (July 2004). (b) PM2.5 concentrations and fluxes at 30 minutes average for $8^{\text {th }}$ July 2004.

efficients observed between PM2.5, PM10 and PTS indicated a predominance of fine particles in the atmospheric aerosol concentrations.

To characterise the local dynamics of aerosol, measurements of PM2.5 concentrations and turbulent fluxes were correlated with meteorological and micrometeorological parameters. Results indicate the presence of a PM2.5 contribution from long-range transport. The event dated July 8, 2004, was considered as an example of long range transport of aerosol in north Italy, including the Venice area. Figure $4 \mathrm{a}$ shows the $24 \mathrm{~h}$ average PM2.5 aerosol concentrations. July 8 shows the highest concentration values for daily averaged PM2.5. The IcoD previsions (www.bsc.es/projects/earthscience/ DREAM) as well as the Earth Probe TOMS (http://toms. gsfc.nasa.gov/aerosols/aerosols_v8.html) showed an African dust transport event from July 6 to July 9 which resulted in a deposition of dust over the Venice lagoon 

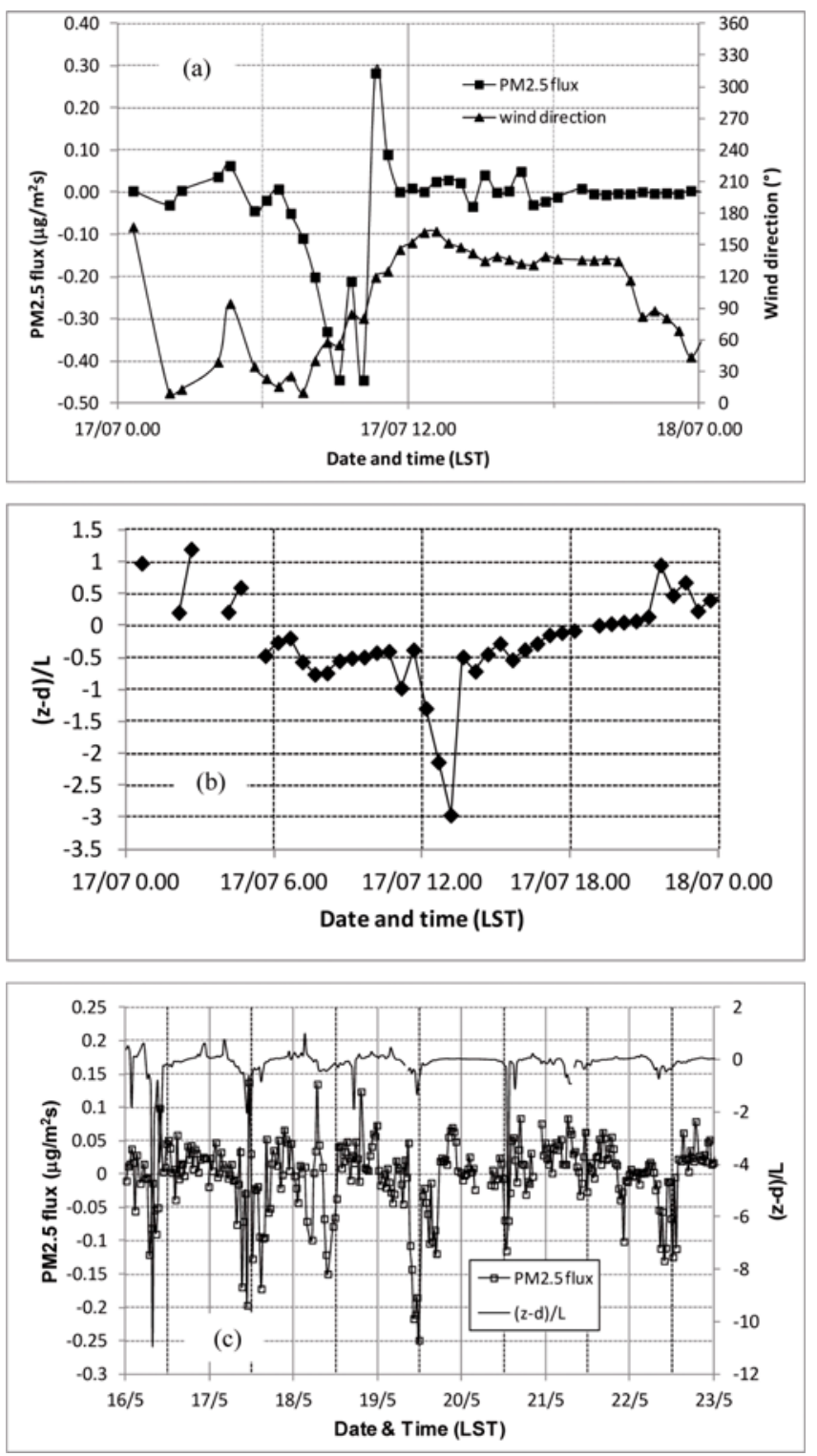

Figure 5: (a) PM2.5 vertical turbulent fluxes and wind direction at 30 minutes average for $17^{\text {th }}$ July 2004. (b) Values of the stability parameter $(z-d) / L$ for $17^{\text {th }}$ July 2004. (c) PM2.5 vertical turbulent fluxes together with stability parameter $(z-d) / L$ for the period between $16^{\text {th }}$ and $23^{\text {th }}$ May 2006.

on July 8 (GAMBARO et al., 2007). This event was visible in Figure $4 \mathrm{~b}$ in terms of PM2.5 concentration and vertical turbulent fluxes, creating a threefold increase in PM2.5 concentration compared to the average value of the campaign and it was characterised by a negative flux (i.e. a deposition) that extended throughout the concentration peak period, which was compatible with an accumulation of aerosol in the area due to particles descending from high altitudes.

Figure 5a shows an example of aerosol deposition (negative flux) observed in correspondence to a change in wind direction, from $\mathrm{N}$ sector to SSE sector. Results showed significant deposition at the starting of the sea breeze in the morning. This could be explained considering that in the morning, when the sea breeze started there is a flow of air mass from the Adriatic Sea, likely less polluted, that mixing with the polluted air coming from land, modified the concentration gradient near the ground establishing a negative aerosol flux. Values of the stability parameter $(z-d) / L$, where $z$ was measurement height, $d$ displacement height and $L$ was Monin-Obukhov length was also reported in Figure $5 \mathrm{~b}$. As shown in Figure 5b atmospheric stability passed from stable condition during night to unstable at sunrise (about 6.00 in the morning). At this period a deposition of PM2.5 (negative turbulent flux) began and continued until noon, when stability condition, gradually, came back toward stable atmosphere, definitively after 18.00 .

This was a frequent situation in the area as shown in Figure $5 \mathrm{c}$ where several negative peaks in aerosol flux (deposition) were observed during the spring measurement campaign. These events are associated to similar meteorological circulations and atmospheric stability conditions (reported in Figure 5c together with aerosol flux).

In Figure 6a the dependence of PM2.5 concentration on wind speed is analysed by evaluating the average concentrations in binned intervals (of $1 \mathrm{~m} / \mathrm{s}$ ) for the two wind direction sectors. In Figure 6 the error bars represented the standard error. The dependence on wind velocity and friction velocity was very similar for the three measurement campaigns (not shown). Results indicated that at low wind speed larger concentrations were observed. In particular larger concentrations were observed for wind directions corresponding to water sector, however, when wind velocity increased, the concentrations in the two wind directions sectors became similar. In Figure $6 \mathrm{~b}$ the same analysis was reported for the deposition velocity $V_{d}$. The observed $V_{d}$ ranges from $-60 \mathrm{~mm} / \mathrm{s}$ to $20 \mathrm{~mm} / \mathrm{s}$, excluding a few outliers. Results indicated that at low wind speed similar deposition velocities were associated to the two wind direction sectors, however at high wind speed significant differences arose, being the fluxes over the water surface positive and larger than the ones over land, with an average negative deposition velocity. A student-t-test has been performed comparing the measured data in the two wind directions sectors (land and water reported in Figure 6) separating case of low wind velocity (lower than $6 \mathrm{~m} / \mathrm{s}$ ) from cases with high wind velocity (higher than $6 \mathrm{~m} / \mathrm{s}$ ).

At high wind speed results indicate that the PM2.5 concentrations are not statistically different in the two wind directions sectors instead the differences in the deposition velocity are statistically significant (at $5 \%$ level). The increase of the positive fluxes from water sector at high wind speed could be due to a contribution of sea spray that has been previously estimated to be between $1 \%$ and $6 \%$ of PM2.5 (PRODI et al., 2009). This could be much more visible in fluxes rather than in concentrations and it could be explained considering 

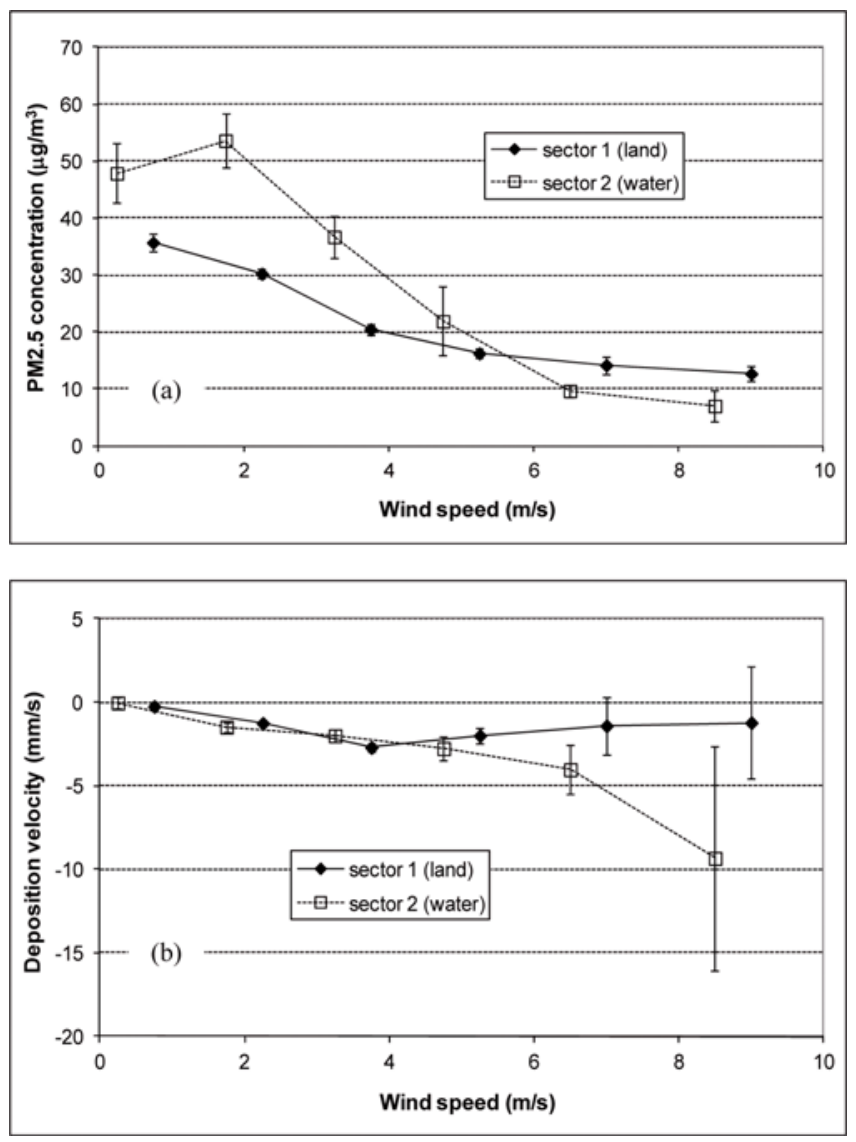

Figure 6: (a) PM2.5 average concentrations against wind speed calculated on $1 \mathrm{~m} / \mathrm{s}$ bin in two different sectors (land and water). (b) Average deposition velocities as function of the wind speed in binned intervals of $1 \mathrm{~m} / \mathrm{s}$ for two wind direction sectors. The results of the second sector have been shifted (backward) of $0.5 \mathrm{~m} / \mathrm{s}$ to easy readability of the figure. In the two graphs all the measurement campaigns are considered together. Error bars represent the standard error.

the results reported in $\mathrm{WU}$ (2000). The analysis of seaspray droplets as function of wind velocity (WU, 2000) shows that the production rate rapidly increases for wind velocity larger than about $6-7 \mathrm{~m} / \mathrm{s}$ due to wave breaking. Further, the intensification of wind speed favours an aerodynamically rough atmospheric surface layer $(\mathrm{WU}$, 1981) that makes the upward transport of droplets more effective. In the specific case of the Venice lagoon, in which there is a relatively large traffic of ships, it is also possible that high wind speed favours the entrainment and the upward transport of sea-spray produced in the wakes of ships.

At low wind speed instead the situation is the opposite with deposition velocities being not significantly different in the two wind direction sectors but concentrations are significantly different (at $5 \%$ level) with concentrations being larger in the water sector. This could be explained considering two aspects. The first is that the water sector is not free from aerosol sources because there is a large traffic of private, public and commercial boats. The second is that the vast majority of cases at low wind speed from the water sector is at time late in the evening and during the night, instead, the cases at low wind speed from the land sector are mainly in diurnal hours. Therefore, the cases at low wind speed from the water sector are mainly in stable conditions with a shallow boundary-layer and this could contribute to the larger concentration observed. At high wind speed the situation is completely different because this are cases in near-neutral conditions

\subsection{Daily patterns in PM2.5 concentrations and turbulent fluxes}

Results reported in Table 1 showed that there was a diurnal cycle in PM2.5 concentrations with average nocturnal levels higher than daytime ones. To analyse this pattern, PM2.5 concentrations and turbulent fluxes were analysed in terms of a 'typical day', averaging all values recorded in a particular hour. Figure 7a reportes the PM2.5 concentration results for three measurement periods, the error bars represent the standard error. A clear daily pattern was revealed, similar in all three campaigns and independent of the absolute concentration values. This daily cycle was further analysed by calculating a mean pattern for hourly concentration fluctuations $C_{f}$, calculated with respect to daily average:

$$
C_{f}=\frac{C-<C>_{\text {daily }}}{<C>_{\text {daily }}}
$$

where $C$ and $<C>_{\text {daily }}$ were, respectively, the hourly and daily average of PM2.5 concentration. Results (Figure $7 \mathrm{~b}$ ) shows that the cycle was similar in the different seasons and it was characterized by a decrease in PM2.5 concentration from 9 am to late afternoon, when a minimum in concentration was reached. This daily pattern was very different from a typical cycle in urban environment (SCHMIDT and KLEMM, 2008; JARVI et al., 2009; ConTINI et al., 2010) where larger concentrations in daytime hours are generally observed, due to local sources, such as vehicular traffic or urban activities. In this measurement site PM2.5 daily concentration pattern seems to be generated by local meteorological circulation. A similar analysis was carried out on the measured atmospheric stability conditions $(z-d) / L$ in Figure 7c and vertical turbulent fluxes in Figure $7 \mathrm{~d}$. During daytime hours the vertical PM2.5 flux was mainly negative in the summer and spring seasons and it was mainly positive in the winter. The aerosol exchange between the surface and atmosphere (positive or negative) was confined, on average, to daytime hours when turbulence of both mechanical and thermal origins was more intense. The observed concentration and flux patterns were likely correlated with meteorological and micrometeorological parameters such as wind direction, relative humidity and boundary layer height (lower in nocturnal hours).

The concentration levels and vertical turbulent fluxes were initially correlated with wind speed and direction. 


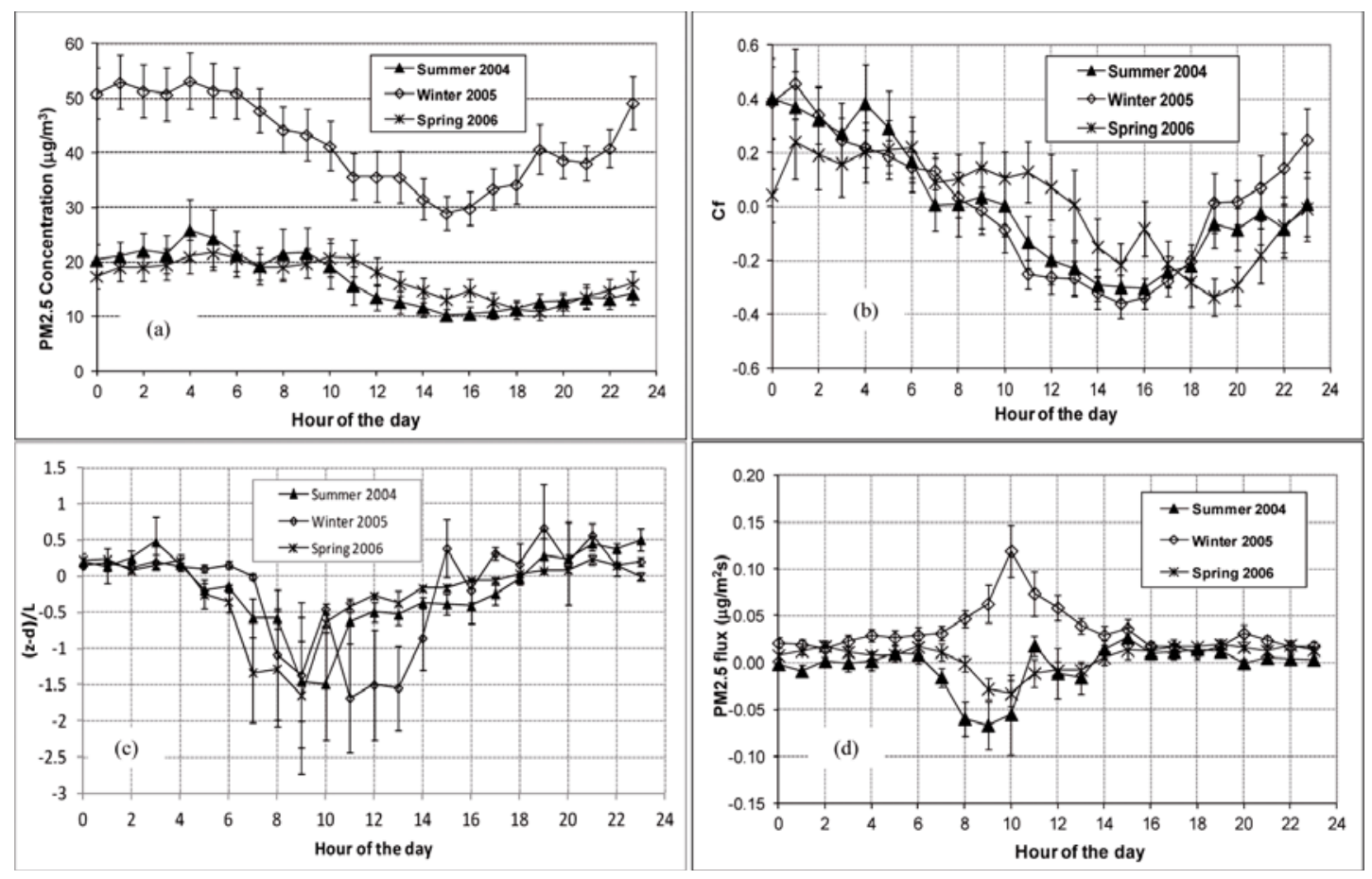

Figure 7: (a) PM2.5 concentration diurnal patterns. (b) PM2.5 normalised concentration diurnal pattern. (c) Atmospheric stability parameter (z-d)/L diurnal pattern. (d) PM2.5 vertical turbulent flux diurnal pattern. In all graphs error bars represent the standard error.

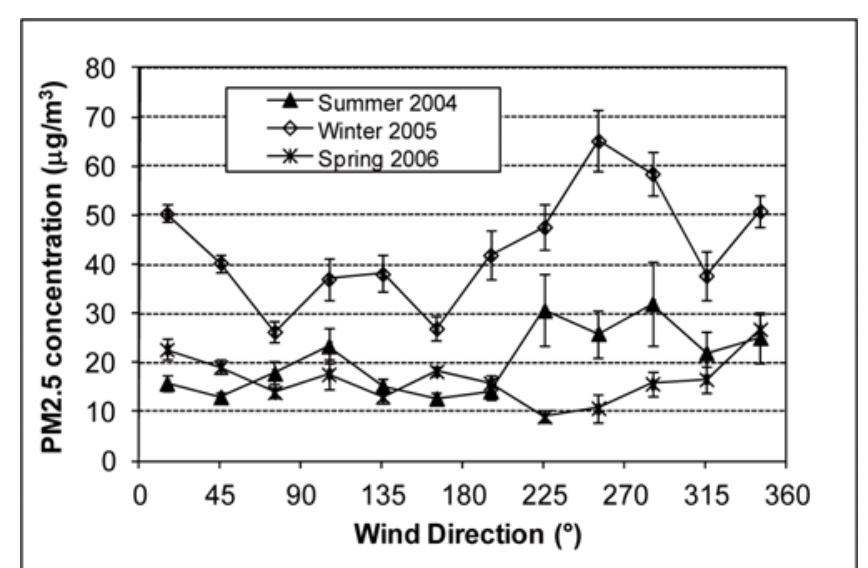

Figure 8: PM2.5 average concentration as function of wind direction calculated in $30^{\circ}$-step intervals for each measurement campaign. Error bars represent the standard error.

Results showed that the average PM2.5 concentration was lower at high wind velocity, because of increased efficiency of transport and diffusion of pollution released by local sources. However, diurnal wind speed patterns for the different measurement campaigns were not significantly correlated with concentration patterns: the Pearson coefficient was 0.43 in the summer, 0.03 in the winter and 0.57 in the spring. Therefore, wind velocity was not the cause of the observed pattern.

The observed daily pattern of prevalent wind direction (shown in Figure 3c) was correlated with the concentration pattern. The Pearson correlation coefficients of the two curves were -0.82 in the summer, -0.87 in the winter and -0.7 in the spring. Given the similarity of the observed patterns among the three measurements campaigns, a correlation analysis was also performed, considering all the campaigns together as a unique dataset to create a larger statistical sample size. The Pearson correlation coefficient was -0.86 on the entire dataset. In order to better investigate this correlation, the PM2.5 concentration mean values were calculated corresponding to $30^{\circ}$-step intervals of wind direction. The results reported in Figure 8 showed an increase in average concentration for the wind direction from the SWNW sector in the winter and summer, while an almost uniform pattern was seen in the spring period. However, the changes in mean concentrations in the different sectors of wind direction were quite small; it was therefore possible that the wind direction was one cause of the diurnal concentration pattern, but it was likely not the primary cause. It has been showed that micrometeorology played a role in the concentration pattern and specifically the boundary-layer height (BLH) (ALFÖLDY et al., 2007; HoLST et al., 2008).

The height of the turbulent atmospheric boundary layer (BLH) was characterized by a typical diurnal cycle, increasing during the daytime because of the typical convective conditions present at daytime with a strong heat flux from the surface, which usually decreased sharply during the night under stable atmospheric conditions. The values of BLH can directly influence the detected concentration levels because they represent the mixing height in which the pollutants emitted near the 
Table 2: Results of varimax rotation of the four principal components (PC) together with the amount of variance explained by each component. The higher the loads of a variable, the more that variable contributes to the variation accounted for by the particular PC. Only loadings with absolute values greater than 0.25 were reported in the table.

\begin{tabular}{ccccc}
\hline & PC 1 & PC 2 & PC 3 & PC 4 \\
\hline PM2.5 conc. $\left(\mu \mathrm{g} / \mathrm{m}^{3}\right)$ & 0.27 & $\mathbf{- 0 . 7 2}$ & & \\
$\mathrm{Vd}(\mathrm{mm} / \mathrm{s})$ & & & 0.30 & $\mathbf{0 . 7 5}$ \\
$\mathrm{u}^{*}(\mathrm{~m} / \mathrm{s})$ & $\mathbf{- 0 . 9 3}$ & & & \\
$(\mathrm{z}-\mathrm{d}) / \mathrm{L}$ & & & 0.38 & $\mathbf{- 0 . 6 5}$ \\
Wind $(\mathrm{m} / \mathrm{s})$ & $\mathbf{- 0 . 9 2}$ & & & \\
Direction $\left({ }^{\circ}\right)$ & 0.27 & & $\mathbf{0 . 6 6}$ & \\
Temperature $\left({ }^{\circ} \mathrm{C}\right)$ & & $\mathbf{0 . 8 4}$ & & \\
Relative Humidity $(\%)$ & & -0.28 & $\mathbf{0 . 6 3}$ & \\
BLH $(\mathrm{m})$ & & $\mathbf{0 . 5 7}$ & -0.48 & \\
Variance $(\%)$ & 26.11 & 18.70 & 11.54 & 10.99 \\
\hline
\end{tabular}

ground are dispersed (SCHÄFER et al., 2006; SCHÄFER et al., 2011). With the measured data, it was possible to evaluate BLH using the results of the micrometeorological station and of a sodar-rass system placed at about $13 \mathrm{~km}$ from our measurement site. A one-dimensional model was used to calculate the time-dependent (hourly) boundary layer height (MARTANO and ROMANELLI, 1997; CONTINI et al., 2009). The algorithm divided the diurnal cycle into two parts, night-time and daytime, according to the sign of the sensible heat flux at the surface. The calculation routine used the temperature lapse rate $(\lambda)$ above and below the temperature inversion height at sunrise, which was the only non-surface parameter that remained to be given as a model input. This parameter was obtained from the sodar-rass temperature profile for the summer and spring measurement campaigns; for the winter campaign, the $\lambda$ measurements were instead taken from radio-soundings in Udine (since the sodar-rass was out of order). The model parameterised the lapse rate below the temperature inversion. The diurnal pattern of BLH was normalised in a way similar to that of the concentrations and it is reported in Figure 9a. The Pearson correlation coefficient with the diurnal pattern of concentration was -0.83 in summer, -0.80 in winter and -0.25 in spring, with a correlation value of -0.78 for the whole data set. The correlation coefficients were higher if they were calculated for a limited period of the day (between midnight and $4 \mathrm{pm}$ ), reaching a maximum of -0.96 in summer, -0.93 in the winter, -0.80 in spring and -0.97 on the whole data set. From Figure 9a, a correlation during the growth of the boundary-layer after sunrise was particularly evident, while the correlation around sunset was much less significant. The changes in concentration after sunrise is explained by the mixing of pollutants accumulated near the ground during stable nocturnal conditions with higher altitude air masses that were relatively less-polluted (on average), thereby decreasing the concentrations as the mixed volume increased. The opposite phenomenon was not seen at sunset because the boundary layer did not collapse towards the ground; rather, what happened at sunset was actually the creation of a new boundary layer that started from the ground, usually with stable (or near neutral) conditions, that developed in the following hours independently of the layer above it. This did not produce a sudden increase in the concentration, but a relatively slow accumulation of pollutants trapped within the low and stable boundary layer. This situation developed over the nocturnal evolution and a new cycle started at the next sunrise. For this reason, the Pearson coefficients were higher if limited to the fraction of the day before sunset because this was actually the period in which concentration was primarily affected by the evolution of the boundary layer. Therefore, our results demonstrated how the boundary layer height was a very important parameter that directly influenced PM2.5 concentration levels and it was likely one of the main factors responsible for the observed diurnal pattern.

The normalized diurnal relative humidity (RHf) pattern was also strongly correlated with the PM2.5 concentration pattern, as shown in Figure 9b. In Figure $9 \mathrm{c}$ the pattern of the actual values of RH is reported and compared to the normalised pattern of concentration. When the PM2.5 and RH patterns measured in the three campaigns are averaged together, a Pearson correlation coefficient of 0.86 was observed. In addition, measurements of the soluble nitrate concentrations in the same site revealed a pronounced diurnal profile, with higher nocturnal concentrations than diurnal concentrations (PRODI et al., 2009). Therefore, the observed daily cycle of PM2.5 concentration was also influenced by the gas-to-particle partitioning of ammonium nitrate precursors $\left(\mathrm{HNO}_{3}\right.$ and $\left.\mathrm{NH}_{3}\right)$, which was favoured by the lower temperature and higher $\mathrm{RH}$ measured during the night and the early morning.

\subsection{Principal Component Analysis (PCA)}

In this work a multivariate statistical technique, Principal Component Analysis (PCA) has been performed to identify major meteorological (wind speed and direction, air temperature, relative humidity) and micrometeorological parameters (friction velocity, Monin Obukhov length, boundary layer height) that influence PM2.5 concentration, turbulent fluxes and deposition 

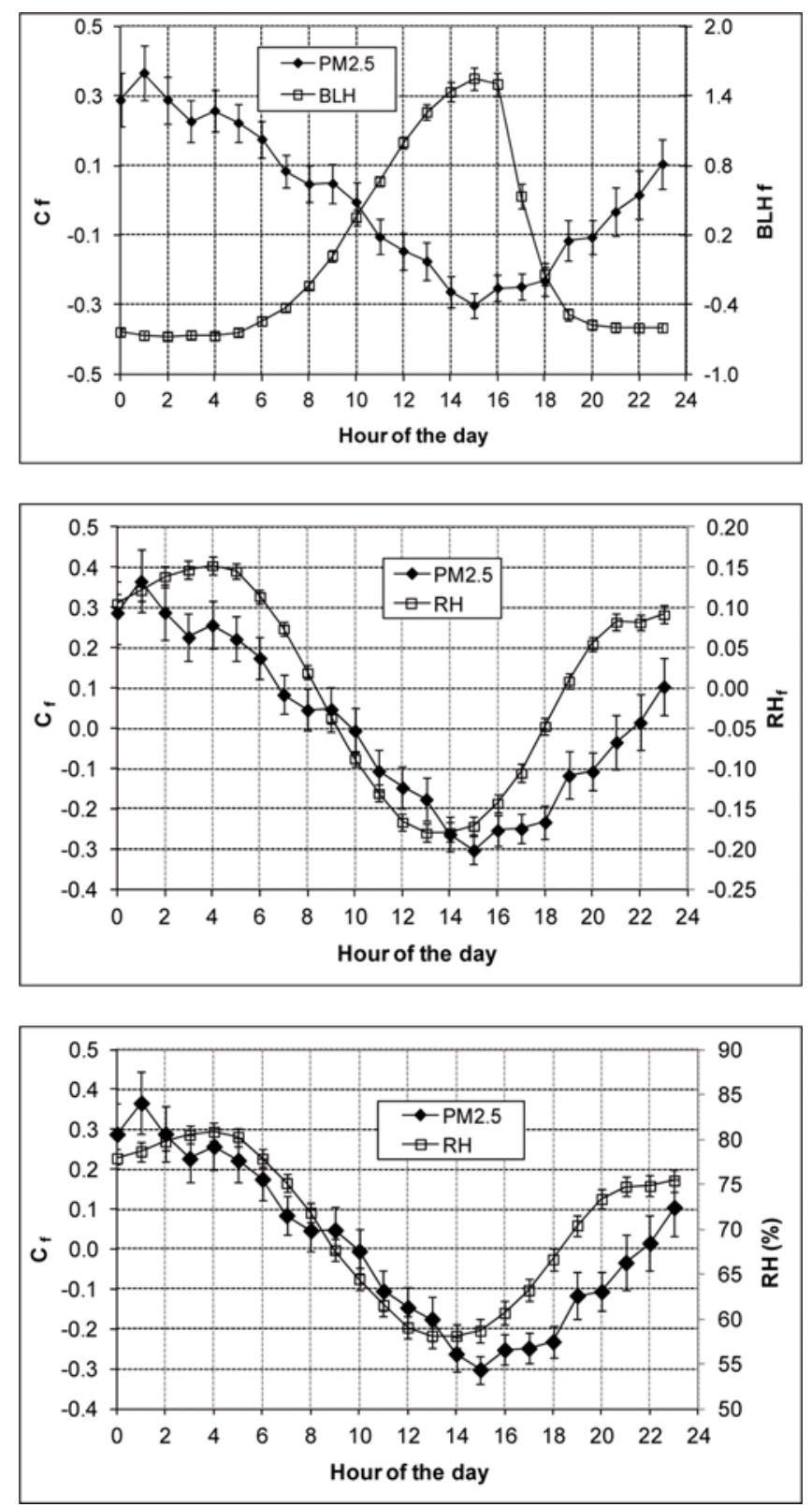

Figure 9: (a) Comparison of the diurnal pattern of normalised boundary layer height and normalised PM2.5 concentration. (b) Comparison of the diurnal pattern of normalised relative humidity and normalised PM2.5 concentration. (c) Comparison of the diurnal pattern of relative humidity and normalised PM2.5 concentration. The analysis is performed over the whole data-set considering together the three measurement campaigns. Error bars represent the standard error.

velocity. In general the purpose of a PCA is to reduce a data set with a large number of variables, $N$, to a data set with fewer new variables, $m<N$, representing a large fraction of the variability contained in the original data. The PCA is widely used in source apportionment of aerosol (VIANA et al., 2008) but also to study correlation between concentration and meteorological parameters (VARDOULAKIS and KASSAMENOS, 2008; HE and LU, 2012). PCA was calculated using software package
STATISTICA 6.0, applying the varimax rotation. Table 2 shows matrix of loads of the four principal components (PC), those having eigenvalues larger than 1, the amount of variance explained by each component. Only loadings with absolute values greater than 0.25 were included in the analysis. From Table 2 it can be seen that PM2.5 concentrations are associated to the first two PCs. The largest influence is on the PC2 (temperature and $\mathrm{BLH})$ that is likely linked to the diurnal cycle and the PC1 (friction velocity and wind velocity) is likely influencing the concentration as shown in Figure 6. The PC4 shows that the deposition velocity is mainly influenced by the stability parameter with a residual influence (PC3) of wind direction and relative humidity.

\section{Conclusions}

In this work, high temporal resolution measurements of PM2.5 concentrations and vertical turbulent fluxes performed on an island of the Venice lagoon in three different seasons were presented and analysed. To characterise the local dynamics, measured atmospheric fine aerosol concentrations and turbulent fluxes were correlated with meteorological and micrometeorological parameters. A seasonal pattern was observed on both PM2.5 concentration and fluxes with winter characterised by higher concentrations and mainly positive fluxes, while summer and spring were characterised by lower concentrations and mainly negative fluxes.

The measured deposition velocities ranged from $60 \mathrm{~mm} / \mathrm{s}$ up to $20 \mathrm{~mm} / \mathrm{s}$ and showed a different behaviour when footprints were over land or over water. Significant emissions were observed over water at high wind speed (larger than $6 \mathrm{~m} / \mathrm{s}$ ), likely as a consequence of marine/salt spray from the lagoon or for a more efficient vertical transport of sea spray generated in the wake of ships. A diurnal cycle in the prevalent wind direction was observed, especially in summer and spring, with nocturnal winds coming from the Alps and diurnal winds from the Adriatic Sea. This influenced deposition velocity with significant negative fluxes observed in the morning at the starting of the sea breeze.

Measurements showed a diurnal pattern with average PM2.5 concentrations smaller during daytime hours compared to nocturnal hours. The forcing of the diurnal concentration cycle was investigated in terms of correlation with wind speed and wind direction. Even if the average concentration was smaller at high wind speed, the diurnal wind speed pattern was different with respect to the aerosol concentration; therefore, the wind speed was not the primary factor responsible for the daily aerosol concentration cycle. Further, the changes in average concentrations as a function of wind direction were relatively limited; therefore, even if the wind direction had a role in creating the observed pattern, it was not the main responsible. The effect of the boundary layer height was 
evaluated using a prognostic model, based on the micrometeorological surface measurement and on sodarrass data. The concentration pattern and the BLH pattern were highly correlated, especially in the boundary layer growth phase at sunrise. The pollutants were trapped near the ground during the night, with a slow increase of concentration that terminated suddenly at sunrise when mixing with elevated air masses took place. This support the conclusion that the BLH cycle was one the primary causes of the daily concentration cycle. Another cause of the cycle could be the chemical equilibrium between ammonium nitrate and its precursors. The cycle of relative humidity was well-correlated to the concentration pattern, and taking into account that the formation of ammonium nitrate and also of secondary organic aerosol, was favoured at low temperature and high humidity, this chemical cycle could play a role in generating the observed pattern. This was in agreement with a previous study of physical and chemical characterisation of aerosols in the same site (PRODI et al., 2009), in which a local generation of nitrate in fine aerosol was inferred. The PCA analysis shows that the stability parameters is mainly influencing the deposition velocity and that BLH and temperature appears to mainly influence the observed concentration levels.

\section{Acknowledgments}

The financial contribution of CORILA (Research Program 2004-2006: Balance of fluxes of organic and inorganic pollutants at the water-air interface of the lagoon of Venice) is gratefully acknowledged. The authors wish to thank Dr. S. FerRARI and Dr. L. Di MATTEO (CNRISAC) for their help in setting up part of the equipment, Dr. P. MARTANo (CNR-ISAC) for useful discussions, the Ente della Zona Industriale di Porto Marghera for providing some meteorological data, Mr. I. ONGARO of University 'Cà Foscari' and Mr. F.M. GRASSO (CNRISAC) for helping with logistical efforts. We thank the anonymous reviewers for their helpful comments.

\section{References}

Alföldy, B., J. OsAn, Z. TOTH, S. TÖRÖK, A. HARBUSCH, C. JAHN, S. EMEIS, K. SCHÄFER, 2007: Aerosol optical depth, aerosol composition and air pollution during summer and winter conditions in Budapest. - Sci. Total Environ. 383, 141-163.

Bettiol, C., F. Collavini, S. Guerzoni, E. MoliNAROLI, P. Rossini, L. Zaggia, R. Zonta, 2005: Atmospheric and riverine inputs of metals, nutrients and persistent organic pollutants into the lagoon of Venice. - Hydrobiology 550, 151-165.

Burgan, O., A. Smargiassi, S. Perron, T. Kosatsky, 2010: Cardiovascular effects of sub-daily levels of ambient fine particles: a systematic review. - Environ. Health 9, 26.

Buzorius, G., Ü. RANNiK, J.M. MÄKelä, T. VESAla, M. KulMALA, 1998: Vertical aerosol particle fluxes measured by eddy covariance technique using condensational particle counter. - J. Aerosol Sci. 29, 157-171.
CAMufFo, D., 1981: Fluctuations in wind direction at Venice, related to the origin of the air masses. - Atmos. Environ. 15, 1543-1551.

Cava D., D. Contini, A. Donateo, P. Martano, 2008: Analysis of short-term closure of the surface energy balance above short vegetation. - Agricult. Forest Meteor. 148, 82-93.

Chakrabarti, B., M.P. Fine, R. Delfino, C. Sioutas, 2004: Performance evaluation of the active-flow personal DataRAM PM2.5 mass monitor (Thermo Anderson pDR1200) designed for continuous personal exposure measurements. - Atmos. Environ. 38, 3329-3340.

Contini, D., D. Cava, P. Martano, A. Donateo, F.M. GRASSO, 2009: Comparison of indirect methods for the estimation of Boundary Layer Height over flat-terrain in a coastal site. - Meteorol. Z. 18, 309-320.

Contini, D., A. Donateo, D. Cesari, F. Belosi, S. FRANCIOSO, 2010: Individuation and characterization of local aerosol sources using high temporal resolution measurements. - J. Environ. Monitor. 12, 1709-1721.

Contini, D., A. Donateo, C. Elefante, F.M. Grasso, 2012. Analysis of particles and carbon dioxide concentrations and fluxes in an urban area: correlation with traffic rate and local micrometeorology. - Atmos. Environ. 46, 25-35.

Dalla Valle, M., A. Marcomini, A. Sfriso, A.J. SWEETMAN, K.C. JONES, 2003: Estimation of PCDD/F distribution and fluxes in the Venice Lagoon, Italy: combining measurement and modelling approaches. - Chemosphere 51, 603-616.

Damay, P.E., D. Maro, A. Coppalle, E. Lamaud, O. Connan, D. Hebert, M. Talbaut, M.Irvine, 2009: Size-resolved eddy covariance measurements of fine particle vertical fluxes. - J. Aerosol Sci. 40, 1050-1058.

Donaldson, K., L. Tran, L.A. Jimenez, R. Duffin, D.E. Newby, N. Mills, W. MacNee, V. Stone, 2005: Combustion derived nanoparticles: a review of their toxicology following inhalation exposure. - Particle and Fibre Toxicology 5/6, 553-560.

Donateo, A., D. Contini, F. Belosi, 2006: Real time measurements of PM2.5 concentrations and vertical turbulent fluxes using an optical detector. - Atmos. Environ. 40, 1346-1360.

Dorsey, J.R., E. Nemitz, M.W. Gallagher, D. Fowler, P.I. WILliams, K.N. BOWER, K.M. BESWICK, 2002: Direct measurements and parameterisation of aerosol flux, concentration and emission velocity above a city. - Atmos. Environ. 36, 791-800.

Gallagher, M.W., K.M. Beswick, J. Duyzer, H. Westrate, T.W. Choularton, P. Hummelshoj, 1997: Measurements of aerosol fluxes to Speulder forest using a micrometeorological technique. - Atmos. Environ. 31, 359-373.

Gallagher M.W., E. Nemitz, J.R. Dorsey, D. Fowler, M.A. Sutton, M. Flynn, J. DuYzer, 2002: Measurements and parameterisations of small aerosol deposition velocities to grassland, arable crops, and forest: influence of surface roughness length on deposition. - J. Geophys. Res. 107, AAC 8-1-AAC8-10.

GAmbaro, A., L. MANOdori, I. Moret, G. CAPOdAGlio, P. CesCON, 2004: Transport of gasphase polycyclic aromatic hydrocarbons to the Venice lagoon. - Environ. Sci. Technol. 38, 5357-5364. 
Gambaro, A., L. Manodori, G. Toscano, D. Contini, A. Donateo, F. Belosi, F. Prodi, P. Cescon, 2007: Organic and Inorganic Compounds in the Venice lagoon PM2.5 and their correlation with micrometeorology. - Annali di Chimica 97, 343-358.

Gambaro, A., M. Radaelli, R. Piazza, A.M. StorTini, D. Contini, F. Belosi, R. Zangrando, P. CESCON, 2009: Organic micropollutants in wet and dry depositions in the Venice Lagoon. - Chemosphere 76, 10171022.

Guerzoni, S., P. Rossini, E. Molinaroli, G. RamPAZZO, S. RACCANELLI, 2004: Measurement of atmospheric deposition of polychlorinated dibenzo-p-dioxins and dibenzofurans in the lagoon of Venice, Italy. - Chemosphere 54, 1309-1317.

Guerzoni, S., G. Rampazzo, E. Molinaroli, P. RosSINI, 2005: Atmospheric bulk deposition to the Lagoon of Venice Part II. Source apportionment analysis near the industrial zone of Porto Marghera, Italy. - Environ. Internat. 31, 975-982.

HE, H., W. LU, 2012: Decomposition of pollution contributors to urban ozone levels concerning regional and local scales. - Build. Environ. 49, 97-103.

Holst, J., H. MAYER, T. Holst, 2008: Effect of meteorological exchange conditions on PM10 concentration. Meteorol. Z. 17, 273-282.

HoRsT, T.W., 1997: A simple formula for attenuation of eddy fluxes measured with first-order response scalar sensor. - Bound.-Layer Meteor. 82, 219-233.

Hsieh, C., G. Katul, T. ChI, 2000: An approximate analytical model for footprint estimation of scalar fluxes in thermally stratified atmospheric flows. - Advan. Water Resour. 23, 765-772.

KELly, F.J., J.C. FuSSELL, 2011: Air pollution and airway disease. - Clinical and Experimental Allergy 41, 10591071.

Kenny, L.C., R.A. Gussman, 1997: Characterization and modelling of a family of cyclone aerosol preseparators. $-\mathrm{J}$. Aerosol Sci. 28, 677-688.

Ibald-Mulli, A., K.L. Timonen, A. Peters, J. HeinRICH, G. WOLKe, T. LANKI, G. BuzOrIUS, W.G. KREYling, J. DE HARTOG, G. HOEK, H.M. TEN BRINK, J. PEKKANEN, 2004: Effects of particulate air pollution on blood pressure and heart rate in subjects with cardiovascular diseases: A multicenter approach. - Environ. Health Perspectives 112, 369-377, DOI:10.1289/ehp.6523.

JARVI, L., RANNIK, I. MAMMARELla, A. SogaChEV, P.P. Aalto, P. Keronen, E. Silvola, M. Kulmala, T. VESALA, 2009: Annual particle flux observations over a heterogeneous urban area. - Atmos. Chem. Phys. 9, 78477856.

MAHRT, L., 1998: Flux Sampling Errors for Aircraft and Towers. - J. Atmos. Ocean. Technol. 15, 416-429.

Marcazzan, G.M., S. Vaccaro, G. Valli, R. VecCHI, 2001: Characterisation of PM10 and PM2.5 particulate matter in the ambient air of Milan (Italy). - Atmos. Environ. 35, 4639-4650.

Marcazzan, G.M., M. Ceriani, G. Valli, R. Vecchi, 2003: Source apportionment of PM10 and PM2.5 in Milan (Italy) using receptor modelling. - Sci. Total Environ. 317, 137-147.

Martano, P., 1996: Valutazione dei flussi turbolenti e della deposizione secca all'interfaccia aria-laguna sulla palude della rosa (Laguna Veneta). - Internal report RI396 ISIATA-CNR (in Italian).
Martano, P., A. Romanelli, 1997: A routine for the calculation of the time-dependent height of the atmospheric boundary layer from surface-layer parameters. - Bound.Layer Meteor. 82, 105-117.

Martensson, E.M., E.D. Nilsson, G. Buzorius, C. JOHANSSON, 2006: Eddy covariance measurements and parameterisation of traffic related particle emissions in an urban environment. - Atmos. Chem. Phys. 6, 769-785.

MCJannet, D.L., F.J. CoOK, R.P. McGlin, H.A. MCGOWAN, S. BURN, 2011. Estimation of evaporation and sensible heat flux from open water using a large aperture scintillometer. - Water Resour. Res. 47, W05545, DOI:10.1029/2010WR010155.

Momi, K., Y. Iто, 2008. Heat budget estimates for Lake Ikeda, Japan. - J. Hydrol. 361, 362-370.

Nemitz, E., J.L. Jimenez, J.A. HufFman, I.M. UlBRICH, M.R. CANagaratna, D.R. Worsnop, A.B. GUENTHER, 2008: An eddy-covariance systems for the measurement of surface/atmosphere exchange fluxes of submicron aerosol chemical species - first application above an urban area. - Aerosol Sci. Technol. 42, 636-657.

PANOFsKy, H.A., J.A.DutTon, 1984: Atmospheric Turbulence - Models and Methods for Engineering Applications. - John Wiley and Sons, New York, 397 pp.

Prodi, F., F. Belosi, D. Contini, G. Santachiara, L. Di Matteo, A. Gambaro, A. Donateo, D. Cesari, 2009: Aerosol fine fraction in the Venice lagoon: particle composition and sources. - Atmos. Res. 92, 141-150.

Pryor, S.C., S.E. LARSEN, L.L. SORENSEN, R.J. BARTHELMIE, 2008: Particle fluxes above forest: observations, methodological considerations and method comparisons. - Environ. Poll. 152, 667-678.

RANNIK, Ü., T. Vesala, 1999: Autoregressive filtering versus linear detrending in estimation of fluxes by the eddy covariance method. - Bound.-Layer Meteor. 91, 259-280.

Rampazzo, G., M. Masiol, F. Visin, B. Pavoni, 2008: Gaseous and PM10-bound pollutants monitored in three sites with differing environmental conditions in the Venice area (Italy). - Water Air Soil Poll. 195, 161-176.

Rossini, P., S. Guerzoni, G. Matteucci, M. GatTOLIN, G. FERrARI, S. RACCANELLI, 2005: Atmospheric fall-out of POPs (PCDD-Fs, PCBs, HCB, PAHs) around the industrial district of Porto Marghera, Italy. - Sci. Total Environ. 349, 190-200.

Scazzola, R., G. Matteucci, S. Guerzoni, E. ChiaMENTI, P. Rossini, E. MOLINAROLI, 2004: Evaluation of trace metal fluxes to soils in hinterland of Porto Marghera industrial zone: comparisons with direct measurements in the Lagoon of Venice. - Water, Air and Soil Poll. 153, 195203.

SchäfER, K., S. EMEIS, H. HofFMANN, C. JAHN, 2006: Influence of mixing layer height upon air pollution in urban and sub-urban areas. - Meteorol. Z. 15, 647-658.

SCHÄFER, K., S. EMEIS, S. SCHRADER, S. TÖRÖK, B. Alföndy, J. Osan, M. Pitz, C. MÜnkel, J. CyRYs, A. Peters, D. Sarigiannis, P. Suppan, 2011: A measurement based analysis of the spatial distribution, temporal variation and chemical composition of particulate matter in Munich and Augsburg. - Meteorol. Z. 20, 47-57.

SCHMidT, A., O. KLEMM, 2008: Direct determination of highly size-resolved turbulent particle fluxes with disjunct eddy covariance and a 12-stage electrical low pressure impactor. - Atmos. Chem. Phys. 8, 7405-7417. 
Stortini, A.M., A. Freda, D. Cesari, W.R.L. CAirns, D. Contini, C. Barbante, F. Prodi, P. Cescon, A. GAMBARO, 2009: An evaluation of the PM2.5 trace elemental composition in the Venice Lagoon area and an analysis of the possible sources. - Atmos. Environ. 43, 62966304.

TodA, M., M. SugitA, 2003: Single level turbulence measurements to determine roughness parameters of complex terrain. - J. Geophys. Res. 108, D12, 4363.

VARDOUlakis, S.,P. KASSAMENOS, 2008: Sources and factors affecting PM10 levels in two European cities: implications for local air quality management. - Atmos. Environ. 42, 3949-3963.

Viana, M., T.A.J. Kuhlbusch, X. Querol, A. Alastuey, R.M. Harrison, P.K. Hopke, W. WinIWARTER, M. VAllius, S. Szidat, A.S.H. Prevot, C. Hueglin, H. Bloemen, P. Wahlin, R. Vecchi, A.I. Miranda, A. Kasper-Giebl, W. Maenhaut, R. HitZANBERGER, 2008: Source apportionment of particulate matter in Europe: a review of methods and results. - J. Aerosol Sci. 39, 827-849.
Webb, E.K., G.I. Pearman, R. Leuning, 1980: Correction of flux measurements for density effects due to heat and water vapour transfer. - Quart. J. Roy. Meteoro. Soc. 106, 85-100.

WU, J., 1981: On critical roughness Reynolds numbers of the atmospheric surface layers. - J. Geophys. Res. 86, 66616665.

WU, J., 2000: Concentration of sea spray droplets at various wind velocities: separating productions through bubble bursting and wind tearing. - J. Phys. Ocean. 30, 195-200. 